$1-1-1986$

\title{
Evidence for the Control of Velocity As Well as Position in Leg Protraction and Retraction by the Stick Insect
}

\author{
J. Dean \\ Cleveland State University, J.DEAN@csuohio.edu \\ H. Cruse \\ Universität Bielefeld
}

Follow this and additional works at: https://engagedscholarship.csuohio.edu/scibges_facpub

Part of the Biology Commons

How does access to this work benefit you? Let us know!

\section{Recommended Citation}

Dean, J. and Cruse, H., "Evidence for the Control of Velocity As Well as Position in Leg Protraction and Retraction by the Stick Insect" (1986). Biological, Geological, and Environmental Faculty Publications. 231. https://engagedscholarship.csuohio.edu/scibges_facpub/231

This Article is brought to you for free and open access by the Biological, Geological, and Environmental Sciences Department at EngagedScholarship@CSU. It has been accepted for inclusion in Biological, Geological, and Environmental Faculty Publications by an authorized administrator of EngagedScholarship@CSU. For more information, please contact library.es@csuohio.edu. 


\title{
Evidence for the Control of Velocity as Well as Position in Leg Protraction and Retraction by the Stick Insect*
}

\author{
J. Dean and H. Cruse \\ Fakultăt für Biologie, Universităt Bielefeld, Postfach 8640, 4800 Bielefeld 1, FRG
}

Observation alone does not reveal the nature of the control system underlying normal walking. In the past, theories about the control principles emphasized first, reflex chains and then later, central oscillators (reviewed by Delcomyn 1980). More recently, the very existence of a central pattern generator has been questioned for stick insect walking (Bässter and Wegner 1983). Nevertheless, the current consensus is that a basic pattern for locomotion may be generated centrally by the nervous system, but this pattern can be significantly shaped and altered by peripheral influences.

Not only the pattern, but also each individual movement, is subject to peripheral control. Precisely defining these peripheral influences has turned out to be a major challenge. Control theory derived from engineering and robotics offers a variety of standard parameters which might be controlled during movement. As summarized in a recent article by Stein (1982), these include position, velocity, force, muscle stiffness, viscosity, and impedance. The parameters actually represented in and controlled by the nervous system are not so easily equated with these terms. To give just one example, even tonic proprioceptors which signal position information usually have some degree of phasic response so that mixing of position and velocity information occurs at the very input to the nervous system. In the present paper, we would like to address this fundamental problem of motor control by examining the leg movements of stick insects during walking.

The rhythmic stepping of a leg can be divided into two phases. The stance or power stroke is the interval in which the leg is in contact with the substrate. During this time the leg can provide support for the body and contribute to propulsion by exerting force against the substrate. The swing or recovery stroke is the interval in which the leg is free of the substrate and moving to a position where it can begin a new stance. During this phase the leg contributes neither support nor propulsion. Two additional terms, retraction and protraction, are often used in the literature on insect locomotion. When a stick insect walks forward, the stance or power stroke typically involves retraction of the leg to the rear while the swing is primarily a protraction of the leg to the front.

The functional requirements placed on stance and swing differ in several important ways and these, in turn, affect the type of experiment that can be performed. Therefore, it is useful to consider these two movements separately in attempting to analyze the way in which they are controlled by the nervous system. (Experiments on the swing were performed by JD; those on the stance by HC. See also Dean 1984 and Cruse 1985a,b.)

* The research was supported by a grant from the Deutsche Forschungsgemeinschaft (Cr58/4), 


\section{SWING PHASE}

By definition, the function of the swing or recovery phase is to return the leg from its position at the end of one power stroke to a position where it can begin a new one. Hence, the main program for the leg controller needs to perform two tasks: it needs, first, to find a substrate for the leg at the end of the swing and, second, to ensure continuous locomotion, it needs to complete the swing quickly enough for the leg to contribute propulsion and support before the remaining legs reach the limits of their stance positions.

With respect to the second task, swing duration, the adult stick insect is an exception. Most insects -walk using a tripod gait in which both swing and stance durations are shortened proportionately with decreases in step period (reviewed in Delcomyn 1981). In contrast, for the adult stick insect the duration of the swing phase is almost constant for all walking speeds under normal conditions (Wendler 1964; Graham 1972). Recently, it has been shown that the load against which the animal is walking affects the speed of the swing phase (Graham 1981). High loading leads to faster swings. This change lengthens the duty cycle of the leg, increasing its contribution to overcoming the increased resistance. Apparently, the large abdomen of the adult stick insect creates a high load and the duration of the swing is minimized.

With respect to the first task, finding a substrate, the stick insect shows a unique adaptation to the irregular structure of its normal arboreal habitat. During the swing, the middle and rear legs are guided towards a suitable foothold by aiming at the location of the ipsilateral front and middle legs, respectively (Cruse 1979, Dean and Wendler 1983). The coordination is such that the target leg is nearing the end of its stance on a load-bearing substrate. Hence, each foothold located by a front leg is used in turn by the ipsilateral middle and rear legs. For their part, the front legs are guided by information from the antennae (Cruse and Krieger, in preparation).

These two features of the main program, shor duration and aiming at a target, make the swing of the stick insect similar to many of the movements considered in studies of motor control in humans and other vertebrates. These sirnilarities make the stick insect movement an attractive model for asking the same basic questions concerning control of movement. In essence, these questions are: first, whether feedback is active in controlling the movement, and if so, what parameters of the movement are controlled?

Unless a movement is so fast as to preclude use of feedback, it does not directly reveal any characteristics of the underlying control. In order to obtain such information, it is usual to perturb the movement in some way and to extrapolate from the elicited changes to the nature of the control system. One common perturbation is to change the load. This was the approach taken in studying the stick insect swing ( $\left.\mathrm{Fi}_{\varepsilon} 1 \mathrm{a}\right)$.

Several possible control mechanisms were tested. The simplest hypothesis is that the leg behaves like a position servomechanism in which the force is simply proportional to the distance between the target position and the current position of the leg (Fig. 2a). If this were the case, then the actual end point of the protraction (AEP: anterior extreme position) should shift caudally when the load is increased. This was tested in the first experiment. Placing the target leg on a fixed platform, as shown in Fig. 1a, ensured that the target position did not change during the movement of the rear leg. 


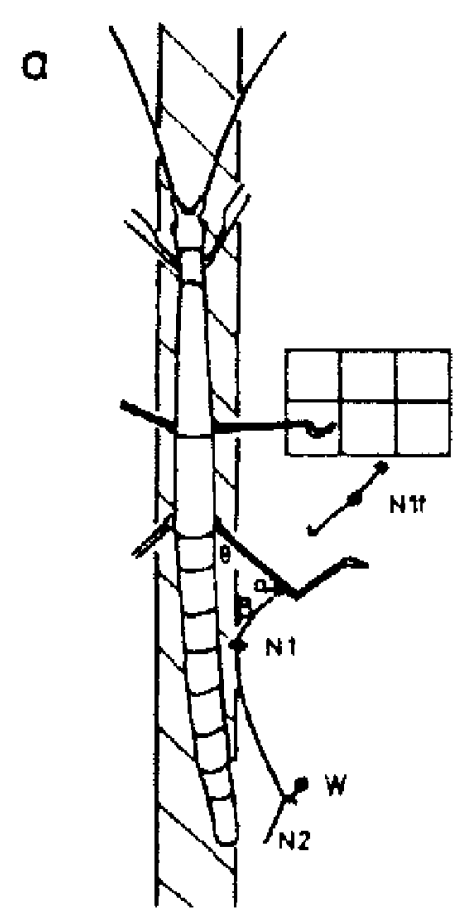

Fig. 1. Method for changing the loat on leg protraction. (a) The inseer is fixed along its dorsal surface to a holder (not shown) and walks by turning a styrofoam treadwheel (cross-hatched band). Weights (W) are attached to a fine thread passing through two guides (N1,N2) and fixed to the distal femur of the right rear leg. The position of $\mathrm{Nl}$ is shown for the condition in which the applied force opposed leg protracion. When the applied force was to aid proraction, N1 was located at N1f, slightly rostral to the metathoracic coxa and just beyond the reach of the femur. In the first series of experiments, the right middle leg. which serves as a target for the rear leg protraction, was placed upon a tixed platform beside the treadwheel. (b) The component of the applied force acting perpendicular to the femur is graphed as a function of leg angle. This component is the effective force opposing (solid line) or aiding (dashed line) leg protraction. (Fig. adapted from Dean 1984)

The end point of the rear leg step was measured first with no added load and then with weights of $110 \mathrm{mg}$ and $250 \mathrm{mg}$ opposing leg protraction. In general, the end point did show a small caudal shift with increased load, but this was not significant for most animals (Dean 1984). In particular, those animals for which the aiming was benter in the control condition showed very little change with increased loading. The weights tested applied forces $14 \mathrm{x}$ and $32 \mathrm{x}$ the calculated maximum force needed by the leg during an unobstructed swing. Therefore, it is evident, first, that the force is not simply proportional to the distance from the target and, second, that feedback is involved in adjusting the force to meet the altered load.

With the platform, only the first step at the stan of walking could be measured. Dynamic effects of loading could be better studied when all six legs were allowed to walk continuously on the treadwheel. Loads were again varied by adding weights to resist the protraction of the right rear leg. Weights of 50 to $750 \mathrm{mg}$ were tested, Increasing the load elicited systematic changes in the leg's movement (Fig. 3). The AEP shifted caudally, the amplitude of the swing decreased, the duration increased, and overall velocity decreased. The decrease in velocity probably reflects basic 

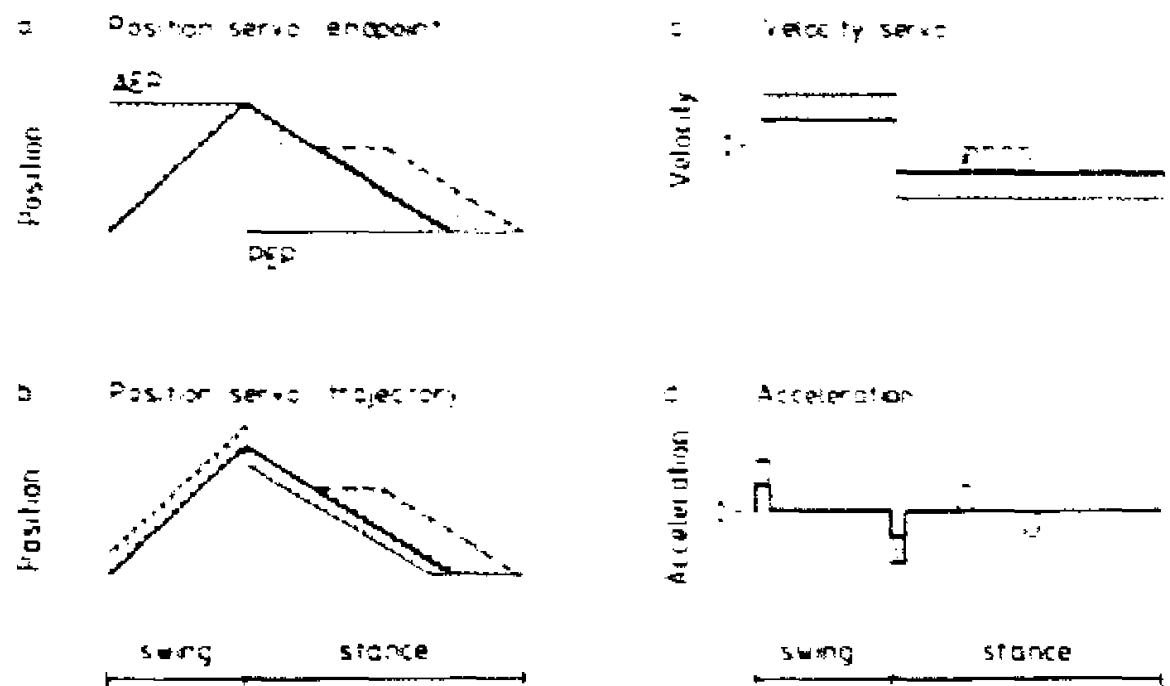



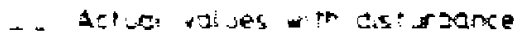

- Reterente nout

Fig. 2. Four different models for control of leg movement during stepping. For each model the thuck solid line represents the actual value and the thin line represents the reference value of the controlled paraneter as a function of tume. The dashed lines deviating from the normal course of retraction tllustrate changes induced when the retraction movement of the leg is temporarily prevented. Musele activation is considered to be proportional to the difference berween actual and reference values (vertical hatched area) The actual force is modified by the low - pass character. istics of the muscles. For position models, the anterior and the postenor extreme points (AEP and PEP) define the end poins of suing and stance, respectively

a) 0

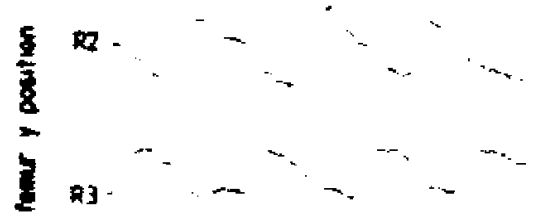

poshon

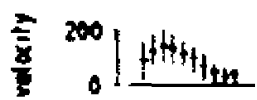

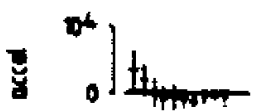

0248
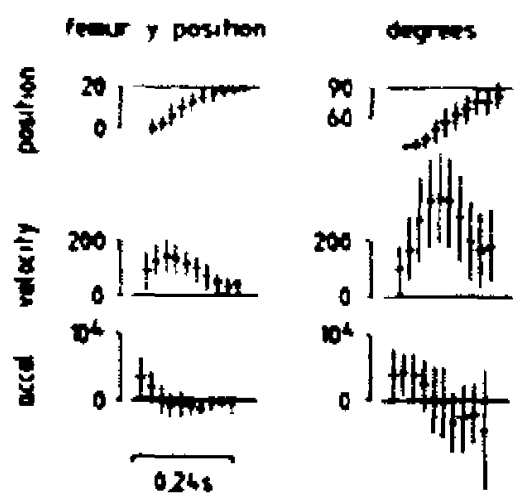

b) $0.25 \mathrm{~g}$

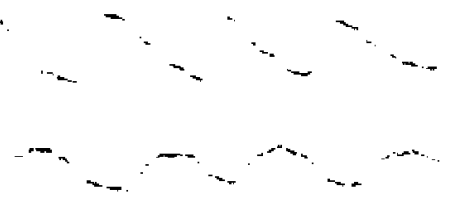

c) 0.699

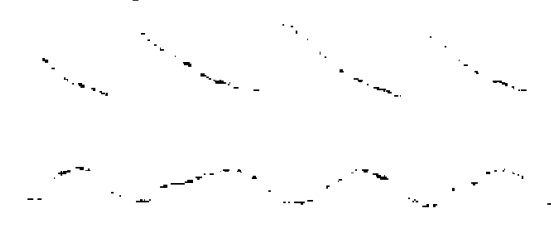

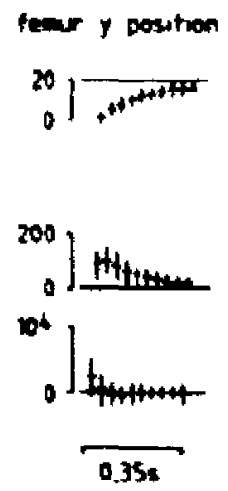
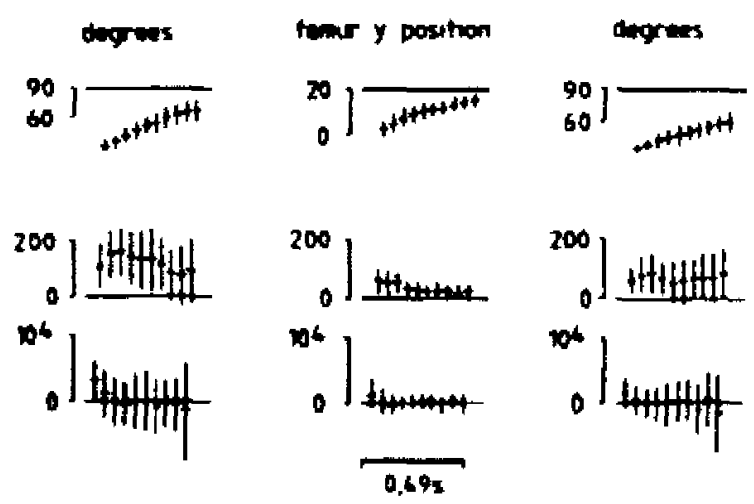
muscle propertes: speed of contraction decreases with increasing lixad. The shift in the AEP might suggest that the targeting reaction no longer was maintained, but this was not entirely the case. The target middle leg continued its retraction durng the prolonged swing of the rear leg. Hence the position of the muddle leg at the time the rear $\mathrm{kg}$ completed its swing was also farther to the rear. This adjustment in the targeting behavor indicates that the turget posmon is not fixed at the stan of the movement.

The speed with which the feedback systems increase the force could be determined only approximately. For these measurements, a stop was positioned to support the weight during the initial part of the string. For the lighter weights of 110 and $250 \mathrm{mg}$, the leg often continued moving forward, albeit with reduced veloxity, through the onset of the opposing force (Fig. 4a). Overcoming the increased load required forces constderably greater than the maximum calculated for unobstructed protractions. Therefore, this observation indicates a response time of less than $20 \mathrm{~ms}$, the limit of resolution for the video recording system.

As a funther test of the "position servo" hypothesis, the rear leg was subjected to forces which aided rather than opposed prorraction. If the leg behaves as a position servo with its reference position set to the end point, then the leg should move forward more rapidly under the influence of the applied weight. This was nor the case: the velocity of the protraction generally did not increase significantly.

A more complicated version of a position servomechanism is one in which the reference position for the servo is not set at the end point but rather moves along a trajectory from the start wo the end point (shown in Fig. 2b, for stance). This model could also be tested with exrernal forces aiding rather than opposing protracton In this case it was assumed that the applied weights would move the leg forward abead of the intended trajectory. leading to a pause or to small retractions when the weight was suddenly removed. Such atwerrations were not usually present (Fig. 4b).

The results concerning the swing phase can to summarized as follows. Position parameters are used to determine the end point of the movement and this information is updated during the swing. Position parameters do no appear to influence the force. Instead it seems that the velocity of the movement is controlled and that muscle force cun be incrensed or decreased or antagonists activated when the veincity varies from that intended.

4 Fig. 3. Effect of force opposing rear leg protraction during continuous walking. Three different load conditions are illustrated in $(a-c)$. Typical steps are shown in the upper row. The two traces represent movement of the rear leg subjected to load (R3) and the ipsilateral middle leg (R2), with protraction corresponding to upward change in the trace. With increasing laating, the protraction movement of the rear leg is prolonged and slower, and the AEP is shifted caudally. The lower row shows averaged protiles for leg position, velocity, and acceleration measured both as femur $y$ position and as leg angle. The durations of the swings were normalized and divided into 10 classes for computing means and standard deviations. The time bars beneath each abscissa show the mean swing duration for each condition. Units on the ordinate are either femur y position, at the left, or degrees, at the right; the corresponding time derivatives are in $\sec ^{-1}$. Femur $y$ position is proportional to tan $(90-\theta)$ : it magnifies changes in leg position for small $\theta$ but is more directly related to tarsus position on the wherel. 
a $\quad 0.11 \mathrm{~g}$ opposing

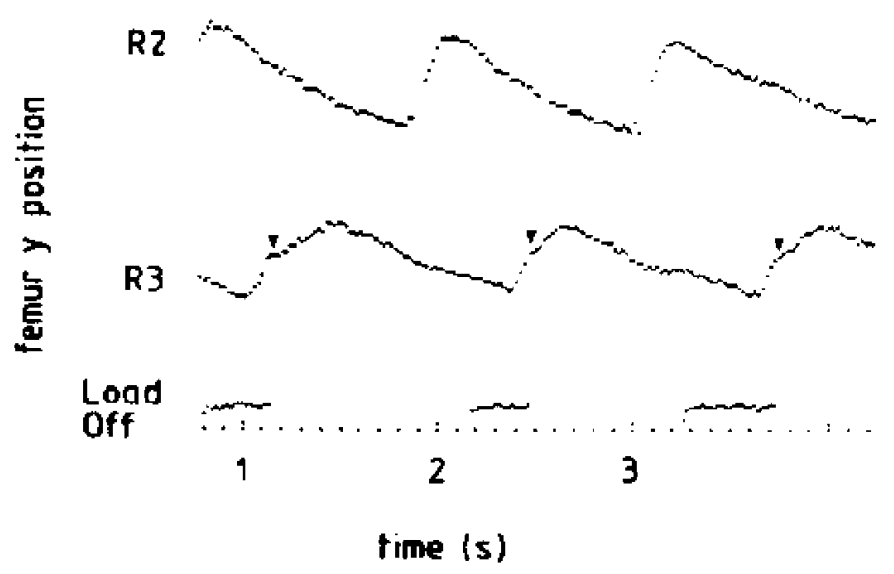

b 0,25 g assisting
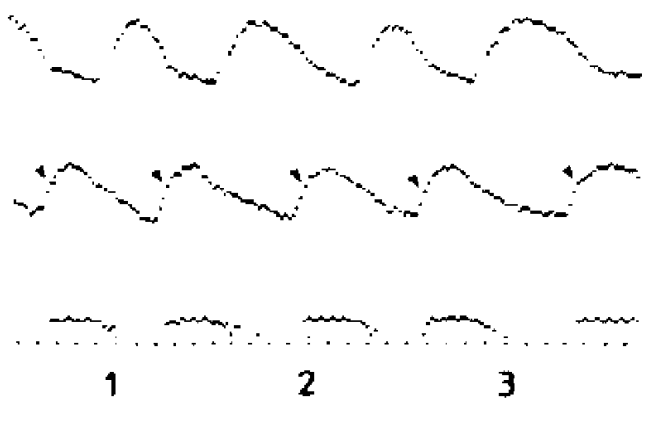

time $(s)$

Fig. 4. Protractions influenced by sudden changes in external force. Representation of leg movement is similar to that in Fig. 3. The line of points above the time axis indicates when the load was being carried by a stop and not acting on the leg. (a) The load opposing rear leg protraction takes effect at the arrows. (b) The force assisting protraction ceases at the arrows. (Figure from Dean 1984)

\section{STANCE PHASE}

The stance is the working part of the leg's cycle. In this phase the leg is contacting the substrate and can contribute to supporting and propelling the body. Because the leg is mechanically coupled through the substrate to all the other supporting legs, the analysis of movement in an individual leg is less straightforward than for the swing. Nevertheless, several features of stance can be characterized by observation. First, the speed of forward progression is directly determined by the speed of leg movement during stance. Since the amplitude of leg movement usually does not change during straight walking, stance duration ulso depends upon walking speed (Graham 1972). Second, the end point of retraction (PEP: posterior extreme position) is determined by a combination of influences both from the leg itself and from intersegmental or central sources. These include the position of the leg as measured by proprioceptors (Bässler 1977, Dean and Wendler 1983), the load on the leg either in the form of cuticle deformation (Bässler 1977) or as the weight supported by the leg (Jander 1985), inhibition arising from an adjacent posterior leg during its swing (Cruse and Epstein 1982), and undefined central oscillations (Cruse and Saxler 1980). Third, although leg retraction in arthropods is often represented as having a constant velocity, for the stick insect, at least, it proceeds in a characteristic "lurching" manner (Graham 1983). Part of the decrease in velocity of leg reiraction is thought to arise through mechanical coupling as other legs oppose forward motion immediately after beginning their stances. Fourth, retraction generally proceeds with a higher speed when the longitudinal resistance is decreased (Graham and Cruse 1981, Epstein and Graham 1983).

More information on the control of individual legs can be gained by adapting a finding of Wendler (1964). When an animal walks on a treadwheel and one leg is placed on a fixed platform beside the wheel, that leg generally remains in stance. The force exerted by the leg in the longitudinal 

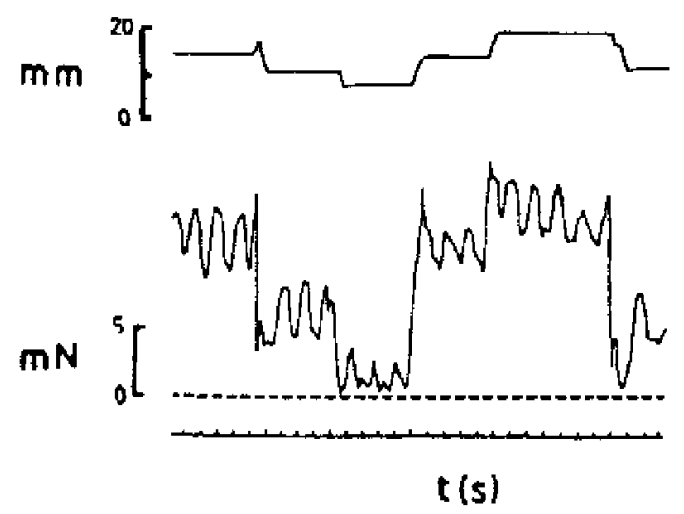

a
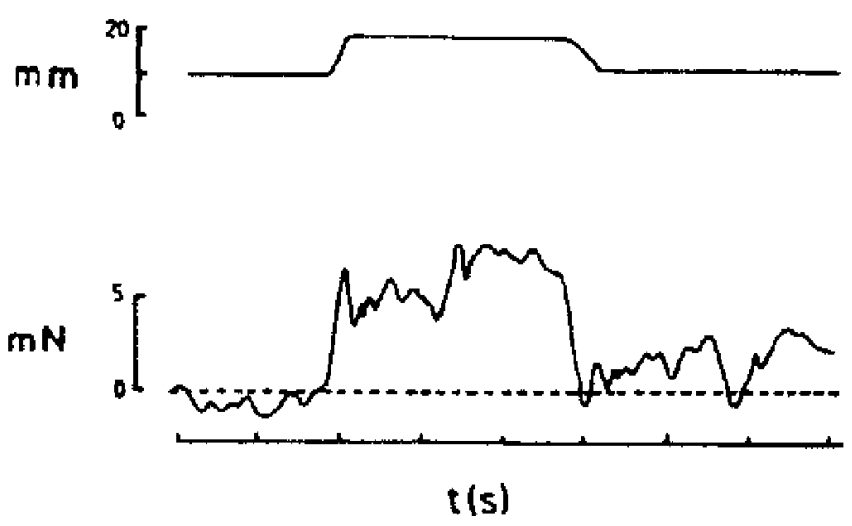

b

Fig. 5. Measurements of retractor force from a front leg standing on a platform. The leg stood on a force transducer which was moved forward and backward by hand. The upper trace shows the position of the platform with anterior being upward; the lower trace shows the force in the anterior-posterior direction with force which would retract the leg shown as positive. The force trace shows large DC changes which parallel the shifts in platform position. The dynamic oscillations around these static levels are coordinated with the leg movements of the walking legs. The measurements were made before (a) and after (b) severing the tendon of the chordotonal organ and thereby removing the major proprioceptive input monitoring position in the anterior-posterior direction. The leg continues to exert more force at anterior positions, which points to properties of muscles and joints rather than proprioceptive loops as the origin of this effect

direction typically can be divided into static and dynamic components (Fig. 5a). The static component can be measured to test hypotheses for the control of stance which are analogous to those already discussed for the swing.

The simplest hypothesis is again that the force exerted by the leg is proportional to the distance from the intended end point (Fig. 2a). According to this model, the mean force exerted by a leg should increase for more rostral platform positions: this is the case, at least qualitatively (Fig. 6). However, it is known that the isometric force which muscles can exert varies with their length. Control measurements made with the major proprioceptive input eliminated showed the same pattern of force changes (Fig. Sb). Therefore, this pattern can be attributed to muscle properties or to lever arm changes.

Hence this finding does not answer the original question of whether the end point position is used to control the force exerted by the retractors. This question can be tested directly by comparing the force curve presented above with one measured while the swing of the adjacent posterior leg is obstructed. The obstruction keeps the posterior leg in continuous swing phase. During its swing the posterior leg inhibits a swing by the adjacent leg (Dean and Wendler 1982). When this inhibition is prolonged, the mean retraction end point of the forward leg shifts caudally (Cruse and Epstein 1982). This inhibition can be demonstrated for leg positions throughout the step (Cruse 1985b). If it is assumed that this actual end point also serves as the target during the movement, then a position servomechanism using this end point as its reference point should produce a parallel shift 


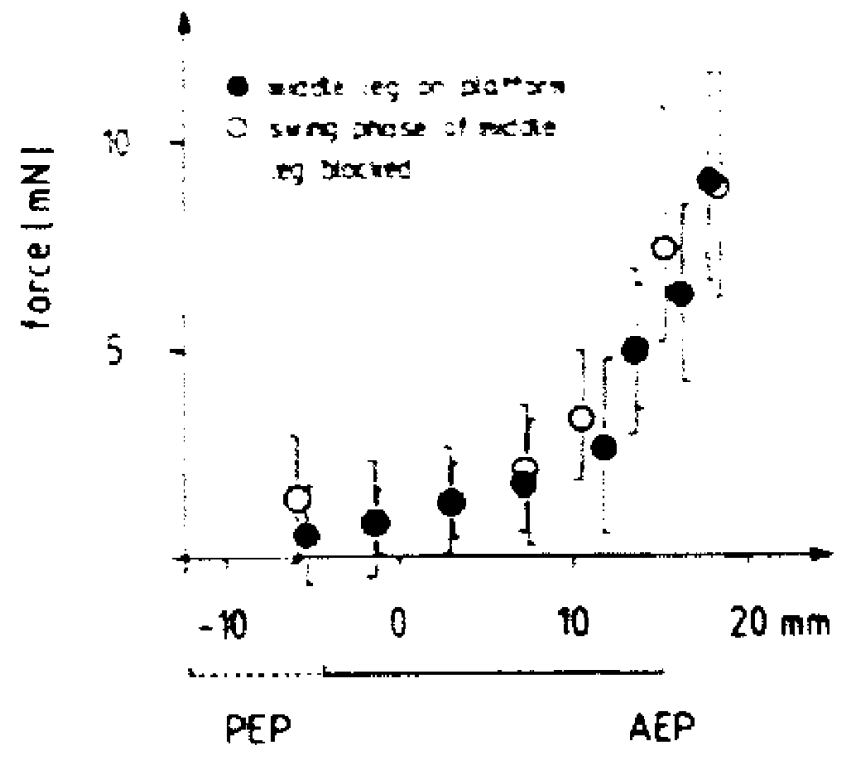

Fig. b. Lak of effect of changed end point on force during retraction. Measurements of the reuaction force of the front leg were made with the ipsilateral middle leg either on a platiorm or whth its swing phase blocked 101 . Otstructung the swing phase causes the retraction end point (PEP) of the front leg to shint caudaly. as indicated by the dasthed line on the abscassa. Never theless. the force exerted by the $\mathrm{kg}$ as a funtron of posinon does not change, indicanng that the position of the end point is no used to determine the force

in the relationshup between force and posituon. In fact. the force curve is unchanged ifig o) Therefore, the altered end point is not involved in determining the retractor force

As was the case for the swing, a funher variant of the position servo hypothesis is one in which the reference inpul is moved along a trajectory. If this trajectory is independent of peripheral feedback, then several predictions can be made about how the force exened by the leg should change when the amual movement is speeded up or slowed down. First, however, it is necessary to measure the force produced by the leg as it moves through a normal retraction (Fig. 7a). This force reaches a maximum miduay in the retraction.

Using this data, the responses predicted for different control models can be formulated (Fig. 2). For a position servomechanism based on a planned trajectory. stopping the movement of the leg should cause the difference between the actual position and the intended trajectory to increase for the duration of the halt and this should be reflected in the force (Fig. 2b). Figure $7 \mathrm{~b}$ shows that this was not the case: after an initial increase, the force actually declines during the halt. (Some initial increase might be expected simply on the basis of muscle properties, but several observations indicate that a large active response is present as well. First, the measured front leg sometimes resists the imposed movement, indicating that the protractors and/or extensors are active. However, If the imposed movement then is stopped, the force reverses direction, indicating that the normal power stroke muscles are turned on. Second. Graham (this volume) presents analogous electrophysiological evidence for activation of protractors or retractors as appropriate to counter torque pulses perturbing the power stroke.) 


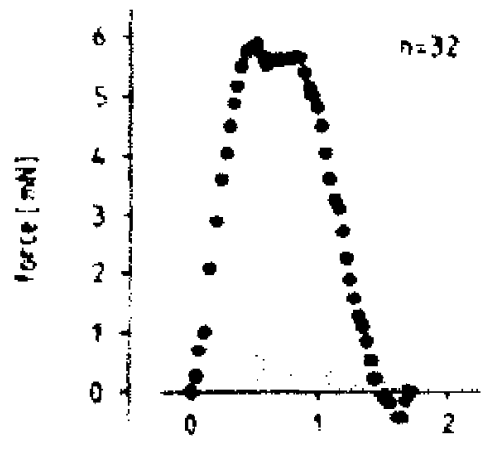

o

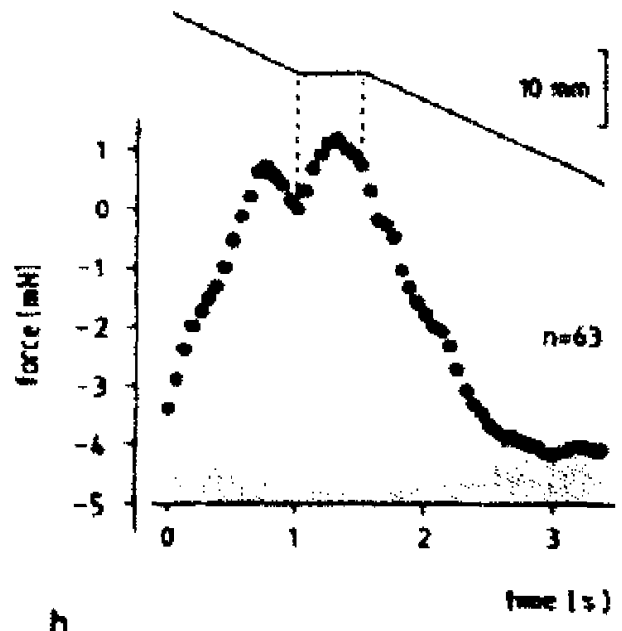

Fig. 7. Measurements of retraction force with and without an interruption in leg movement. Measurements were made by moving a force transducer theside the treadwhel at abour the walking speed and recording the force when a leg stepped on the transducer. The trace at the top illustrales the movernent of the transducer and leg. (a) The cransducer was moved smoothly throughout the retraction. (b) The transtucer was halled briefy during the retraction. When leg movement is prevented, the force record shows a maximum. This partern test lits a model in which force is derived from a combination of velocity and acceleration signals (models $c$ and $d$ in Fig. 2). The sizes of the standard devianons are shown by the dented area above the abscissa

If prostion is not the paraneter controlling the force exerted ty the leg. What other possibilities are there': One is movement veliculy. the tirst derivative of position. If the leg is antempeing to mantain a constant velocity. then stoppong it should restal in a constant devation between the desired velocity and the actual velocity (Fig. 20 ). If thes deviation is the input to the force controller, then force should remain comstant for the duration of the halt. This is better approximation to the observed results but sill not completely atcusate. The decline in the force as the halt is maintaned suggests that acceleration, the second dervatuve of posituon, also affects the force (Fig. 2d). Our measurements are not sutfictent to determine the exact relationship of output force to either velocity or accelerauon and thus do not ineet a strict definition of "control". Therefore we will use the expression "velocity sensitive combul".

\section{CONCLUSION}

The preceding discussion has treated the swing and stance movements separately, but it should be clear that there are many simularites in their control. First, as many previous studies have demonstrated, peripheral leedback greatly influences the motor pattern during walking and this is true both for swing and for stance. These peripheral influences include both the position of the leg and the load upon it. However, the results presented here show that different movement parameters influence different aspects of the movement. Position information is involved in the decision to terminate both swing and stance. The position of the target leg provides the most important criterion for ending the swing phase and the position of the protracting leg determines when this criterion is met. Proprioceptive information from both the target leg and the moving $\mathrm{leg}$ 
is involved (Cruse et al. 1984; Dean and Wendler 1983). Position is one of several factors contributing to ending the stance phase. A second factor is the load on the leg both in the axial and in the vertical directions. A third factor is coordination from intersegmental or central sources. Inhibition during the swing of the adjacent caudal leg causes the PEP to move caudally. Undefined central sources cause the force excrted by a leg held at a constant position to vary in thythm with the walking legs. This influence could arise either from a central oscillator for the leg or from coordination signals transmitted from the other legs. In either case, it could affect the stance end point either indirectly by way of the self-induced loading on the leg or directly through the relevant interneurons.

Position information does not appear to be important in determining the force developed by the muscles during the movement. Neither the position of the end point to be reached nor proprioceptive input signalling leg position affect the output force. Force does vary as a function of position due to the geometry of the joints and the mechanical properties of the muscles involved, but these factors are not under the control of the nervous system.

The nervous system does modulate force in response both to deviations from the normal velocity and, to some extent, to the accelerations accompanying these deviations. This amounts to a velocity sensitive control during movement. For both stance and swing, the velocity of the movement has a direct bearing on the overall performance of locomotion. During stance, retraction velocity governs the speed of forward locomotion; during swing, protraction velocity enables the leg to assume its stance position at the proper time. Therefore, it is appropriate that the velocity of the leg movement be controlled in the longitudinal plane. In other planes, other parancters may he more appropriate. For example, position information is surely important for controlling the height of the body during stance.

The swing movement, and the stance to a lesser extent, rosemble what have been called fast ramp movements in vertebrates (Desmedt and Godaux 1978). These are rapid movements in which muscle activity continues throughout the movernent. As in the stick insect, rapid reflex pathways are active to meet variations in load. The normal load for the swing is simply the mass of the moving limb. This load is predictable and load compensation probably plays a negligible role in normal walking. For the stance, the load can vary considerably depending upon the insect's orientation with respect to gravity.

The findings presented above and those from the literaturc can be used to construct the diagram of the leg controller shown in Fig. 8. This figure separates factors affecting the termination of a step phase from factors which influence the output force during a phase. The first group, which includes position information, contains factors which can be considered part of the oscillator. The second group, which includes velocity, contains those which participate in a servomechanism. The separation made here does nor necessarily correspond to structural separation in the nervous system. Force compensation could occur either through feedback at the motoneuron or at the interneuron level. Nevertheless, it is interesting to compare the scheme presented here with recent physiological findings in the locust flight system. In the steering pathways from the ocelli, the sensory input has a weak direct effect on motoneurons but the stronger effect is on premotor interneurons which are not part of the fight oscillator (Reichert et al. 1985).

Acknowledgements. We are grateful to D. Forsythe for helpful criticism of the manuscript, 


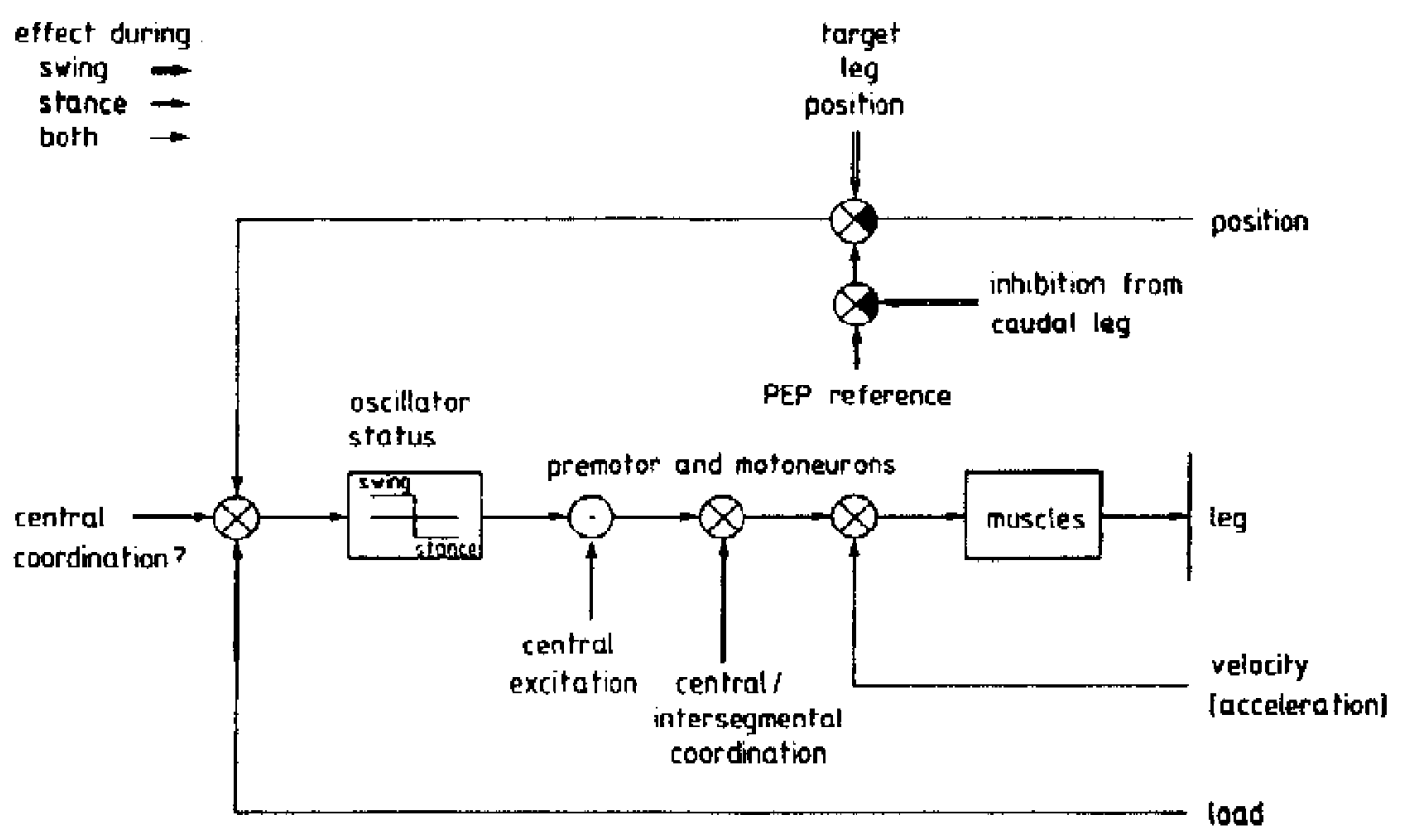

Fig. 8. A schematic summary of control influences during stepping. The leg and various paraIneters of its motion are represented on the right margin. Factors considered part of the oscillator act on the oscillator status box at the left and control switching between stance and swing. Factors affecting movement during a phase enter the control path between oscillator and muscles

\section{REFERENCES}

Bässler U (1977) Sensory control of leg movement in the stick insect Carausius morosus. Biol Cybern 25: $61-72$

Bässler U, Wegner $U$ (1983) Motor output of the denervated thoracic ventral nerve cord in the stick insect Carausius morosus. J Exp Biol 105: $127-145$

Cruse $H$ (1979) The control of the anterior extreme position of the hindleg of a walking stick insect, Carausius morosus. Physiol Entomol 4: 121-124

Cruse H (1985a) Which parameters control the leg movement of a walking insect? I. Velocity control during the stance phase. J Exp Biol 116: 34:3-355

Cruse $\mathrm{H}$ (1985b) Which parameters control the leg movement of a walking insect? II. The start of the swing phase. J Exp Biol 116: 357-362

Cruse H, Saxler G (1980) The coordination of force oscillations and of leg movement in a walking insect (Carausius morosus). Biol Cybern 36: $165-171$

Cruse H, Epstein S (1982) Peripheral influences on the movement of the legs in a walking insect Carausius morosus. J Exp Biol 101: $161-170$ 
Cruse H, Dean J, Suilmann M (1984) The contributions of diverse sense organs to the control of leg movement by a walking insect. J Comp Physiol A 154: 695-705

Dean I (1984) Control of leg protraction in the stick insect: a targeted movement showing compensation for externally applied forces. J Comp Physiol A 155: $771-781$

Dean $\mathrm{J}$, Wendier $\mathrm{G}$ (1982) Stick insects walking on a wheel: perturbations induced by obstruction of leg protraction. J Comp Physiol 148: 195-207

Dean J, Wendler G (1983) Stick insect locomotion on a walking wheel: interleg coordination of leg position. J Exp Biol 103: $75-94$

Delcomyn F (1980) Neural basis of rhythmic behavior in animals. Science 210: $492-498$

Delcomyn F (1981) Insect locomotion on land. In: Herreid CF II, Fourtner CR (eds) I.ocomotion and energetics in arthropods. Plenum, NY, pp 103-125

Desmedt JE, Godaux E (1978) Ballistic skilled movements: load compensation and patterning of the motor commands. In: Desmedt JE (ed) Cerebral motor control in man: long loop mechanisms. Karger, Basel, pp 21-55 (Progress in clinical neurophysiology, vol 4)

Epstein S, Graham D (1983) Behaviour and motor output of stick insects walking on a slippery surface. I. Forward walking. J Exp Biol 105: 215-229

Graham D (1972) An analysis of walking movements in the first instar and adult stick insect. J Comp Physiol 81: $23-52$

Graham D (1981) Waiking kinetics of the stick insect using a low-inertia counter-balanced pair of independent tread - wheels. Biol Cybern 40:49-57

Graham D (1983) Insects are both impeded and propelled by their legs during walking. J Exp Biol 104: $129-137$

Graham D, Cruse $H$ (1981) Coordinated walking of stick insects on a mercury surface. J Exp Biol 92: $229-241$

Jander JP (1985) Mechanical stability in stick insects when walking straight and around curves. In: Gewecke M, Wendler G (eds) Insect locomotion. Parey, Hamburg, pp 33-42

Reichert H, Rowell CHF, Griss C (1985) Course correction circuitry translates feature detection into behavioural action in locusts. Nature 315: 142-144

Stein RB (1982) What muscle variable(s) does the nervous system control in limb movements? Behav Brain Sci 5: $535-577$

Wendler G (1964) Laufen und Stehen der Stabheuschrecke Carausius morosus: Sinnesborstenfelder in den Beingelenken als Glieder von Regelkreisen. Z Vergl Physiol 48: 198-250 


\section{Subject Index}

action imagery questionnaire 192 action-language bridge 187 actor-environment relationship 145 afferent phase angle information 119 apraxia 3,187

areas, s. Brodmann's cortical fields

arm trajectory planning 41-5I

association cortex 7

attractors 110,131

basal ganglia

- putamen 5

$\because$ palijum 5,7

- caudate nucleus 5

bejl-shaped velocity profiles 147 , 249

Bereitschaftspotential $8,28-33$

Bewegungsentwurf 3

bilabial gestures 136

bimanual deficit 8

- phase transtions 121

block of movement 237

body space equations 133

Brodmann's cortical fields

- , area 6 3-5, 33

- area 4 (s. Motor cortex) 5, $14-24,33$

- , area $514-24$

-, area 7 14-24

- area 3b 19

$\because$ area 119

categories of general skills 148 cat locomotion 109

central feedback 24

cerebel $1 \mathrm{um}$

- latera? 7,24

- dentate nucieus $7,14-24$

- interpositus nucleus 14-24

- cerebellar hemispherectomy 28

cerebral blood flow (CBF) 8

choice reaction time task 64-70. $91-98$

chordotonal organ 253

closed-loop feedback control 107

cocontraction 233

compensation of perturbations

$\because$ autogenic 107-108
-, remote 107.108

- functionally specific 107-108

-, immediate 130, 139

- task-specific 130

conditioning stimuli 14 contingent negative variation (CNV)
$29-37$

coordinative structures 105-109, 131

corollary discharge 24

coupling between the limbs 237

cyclic bilabial gestures 140

cytoarchitectonic areas s. Brodmann's cortical fields

deafferentation 14

delayed auditory feedback 184-185

dentate nucleus 5 . cerebellum

descending steep slopes 257-258

diving ganmet 224

drawing movements 201

-, geometrical and kinematical relations 201

- temporal planning 204

- elliptic movements 205

dynamic control regime 109-115

dysgraphic 177

effector system 129

efference copy 24

EMG duration and amplitude 233

end-point control 50, 113-114

evoked potential 31

external feedback $183-184$

extero-proprio relationship 217

extrinsic timing information 226

figural unit of motor action 210

final position control 50

Fitts equation 247

force

- isometric 29

- grasping 161-163

- frictional 162

- anticipated 167

- time to peak 233

- time profile 244-247

- and position 270

force-velocity relationship 238

functional synergies

s. "coordinative structures" 